Original Research Paper

\title{
Pemeriksaan Kesehatan Untuk Deteksi Dan Pengelolaan Diabetes Mellitus dan Hiperkolestrol
}

\author{
Aini $^{1 *}$, Nuratikah ${ }^{2}$, Jumari Ustiawaty ${ }^{3}$, Made Sriasih ${ }^{4}$ \\ ${ }^{1,3}$ Program Studi Teknologi Laboratorium Medik, Politeknik Medica Farma Husada Mataram, Kota \\ Mataram, Nusa TenggaraBarat \\ ${ }^{2}$ Program Studi Farmasi, Politeknik Medica Farma Husada Mataram, Kota Mataram, NusaTenggara Barat \\ ${ }^{4}$ Magister Manajemen Sumber Daya Peternakan Universitas Mataram
}

DOI: https://doi.org/10.29303/jpmpi.v4i2.670

Sitasi: Aini., Nuratikah., Ustiawaty, J., \& Sriasih, M. (2021). Pemeriksaan Kesehatan Untuk Deteksi Dan Pengelolaan Diabetes Mellitus dan Hiperkolestrol. Jurnal Pengabdian Magister Pendidikan IPA, 4(2)

\section{Article History}

Received: 03 Februari 2021

Revised: 08 Maret 2021

Accepted: 06 April 2021

*Corresponding Author:

Aini,

Program Studi Teknologi

Laboratorium Medik,

Politeknik Medica Farma

Husada Mataram,

Kota Mataram,

Nusa Tenggara Barat; ainie.mfh@gmail.com

\begin{abstract}
Diabetes Melitus (DM) merupakan penyakit yang berhubungan dengan sindrom yang memiliki ciri meningkatnya kadar glukosa darah atau dikenal dengan istilah hiperglikemia.Kondisi hiperglikemia ini dapat terjadi akibat gangguan sekresi, kerja insulin, atau oleh keduanya. Penyakit kronis seperti DM sangat rentan terhadap gangguan fungsi yang bisa menyebabkan kegagalan padaorgan mata,ginjal,saraf, jantung dan pembuluh darah. Kolestrol adalah suatu molekul atau komponen lemak di dalam sel. Lemak merupakan slah satu zat gizi yang sangat diperlukan oleh tubuh.lemak merupakan sumber energi yang memberikan kalori paling tinggi tetapi bila terdapat kadar kolestrol yang tinggi (hiperkolestrol) dapat menimbulkan resiko yang tinggi. Pemeriksaan kesehatan (screning) kesehatan) belum menjadi kebiasaan masayakat pada umumnya, hal ini disebabkan karena kurangnya pengetahuan masyakat tentang screening kesehatan ataupun penyakit degeneratif dan kurangnya biaya dalam masyakat untuk melakukan pemeriksaan kesehatan secara rutin. Dapat disimpulkan bahwa pada saat pemeriksaan dilakukan di Bawaq Bageq Utara kelurahan Dasan Agung kecamatan Selaparang kota Mataram Jumlah responden yang datang sebanyak 37 orang warga. Hasil pemeriksaan diperoleh hasil warga yang hipertensi $56,7 \%$ (21 orang) dan $43.2 \%$ (16 orang) mempunyai kadar kolesterol di atas normal dan membutuhkan pengobatan.
\end{abstract}

Keywords: Diabetes Mellitus; Hiperkolestrol; Insulin; Penyakit Degeneratif.

\section{Pendahuluan}

Diabetes Melitus (DM) merupakan penyakit yang berhubungan dengan sindrom metabolik yang memiliki ciri meningkatnya kadar glukosa darah atau dikenal dengan istilah hiperglikemia. Kondisi hiperglikemia ini dapat terjadi akibat gangguan sekresi, kerja insulin, atau oleh keduanya (Soelistijo et al., 2015). Penyakit kronis seperti DM sangat rentan terhadap gangguan fungsi yang bisa menyebabkan kegagalan pada organ mata, ginjal,saraf, jantung dan pembuluh darah (World Health Organization, 2016).

Kolestrol adalah suatu molekul atau komponen lemak di dalam sel. Lemak 
merupakan salah satu zat gizi yang sangat diperlukan oleh tubuh lemak merupakan sumber energi yang memberikan kalori paling tinggi tetapi bila terdapat kadar kolestrol yang tinggi (hiperkolestrol) dapat menimbulkan resiko yang tinggi (Mahatidanar, 2015).

Pemeriksaan kesehatan secara rutin merupakan langkah awal untuk mengetahui lebih dini tentang penyakit degeneratif dan berkembangnya penyakit degeneratif. Pemeriksaan kesehatan (screening kesehatan) belum menjadi kebiasaan masyarakat pada umumnya, hal ini disebabkan karena kurangnya pengetahuan masyarakat tentang screening kesehatan ataupun penyakit degeneratif dan kurangnya biaya dalam masyakat untuk melakukan pemeriksaan kesehatan secara rutin. Banyak masyarakat belum pernah melakukan deteksi dini untuk penyakit DM banyak masyarakat terdiagnosa DM tetapi tidak sejak dini, diketahui setelah rawat inap dan banyak pasien DM yang meninggal karena terlambat penanganannya. Saat ini upaya penangulangan penyakit DM belum menjadi prioritas utama dalam pelayanan kesehatan walaupun diketahui komplikasi yang dapat ditimbulkan cukup parah seperti penyakit jantung kronis, hipertensi, sistem saraf mata, hati, dan ginjal (Depkes, 2003)

Pemeriksaan gula darah dan kolestrol dapat digunakan untuk mengidentifikasi metabolisme yang terjadi di dalam tubuh. Sehingga jika terjadi peningkatan yang melewati nilai normal dapat digunakan sebagai langkah awal untuk melakukan merubah pola hidup sehingga dapat mengurangi terjadi komplikasi dari penyakit diabetes mellitus (DM) dan hiperkolestrol. Penyakit degeneratif seperti Diabetes mellitus dan hiperkolestrol dapat terjadi pada semua orang tanpa memandang umur, suku, dan wilayah.

Dari uraian diatas pemeriksaan gula darah dan kolestrol secara rutin dapat digunakan untuk deteksi dini penyakit DM dan hiperkolestrol untuk mencegah atau memperlambat terjadinya komplikasi. Banyak masyarakat yang belum paham pentingnya melakukan pemeriksaan gula darah dan kolestrol dan kurangnya biaya untuk melakukan pemeriksaan secara rutin sehingga banyak terjadi komplikasi pada penderita DM atau hiperkolestrol. Oleh karena itu dalam rangka mewujudkan sumber daya manusia yang sehat perlu dilakukan pemeriksaan kesehatan yang merupakan langkah awal untuk deteksi dini dari penyakit degeneratif seperti DM, dan hiperkolesterol.

\section{Metode}

Metode pelaksanaan dalam kegiatan ini yaitu dalam bentuk ceramah sekaligus diskusi tentang materi DM dan hiperkolestrol.Selanjutnya dilakukan pemeriksaan kesehatan pada masyarakat yang ada di lingkungan Bawaq Bageq Utara kelurahan Dasan Agung kecamatan Selaparang Kota Mataram. Tahapan kegiatan yang dilakukan adalah ceramah diskusi, dan pemeriksaan kesehatan. Pemeriksaan kesehatan dikuti oleh 37 peserta. Masing masing peserta dilakukan pemeriksaan kesehatan yang meliputi pengecekan tekanan darah, pengukuran kadar kolesterol, dan pengukuran kadar gula darah.

Tabel 1. Susunan Acara Kegiatan

\begin{tabular}{|c|c|c|c|}
\hline No & Materi Kegiatan & Penyaji & waktu \\
\hline 1 & $\begin{array}{l}\text { Pengertian DM dan } \\
\text { cara pencegahan }\end{array}$ & $\begin{array}{l}\text { Aini, } \\
\text { S.Si., } \\
\text { M.Si }\end{array}$ & $\begin{array}{l}14.30- \\
14.45\end{array}$ \\
\hline 2 & $\begin{array}{l}\text { Hiperkolestrol dan } \\
\text { Cara pencegahan }\end{array}$ & $\begin{array}{l}\text { Jumari } \\
\text { Ustiawaty } \\
\text {, S.Si., } \\
\text { M.Si }\end{array}$ & $\begin{array}{l}14.45- \\
15.00\end{array}$ \\
\hline 3 & $\begin{array}{l}\text { Diskusi untuk } \\
\text { mengakomodasi } \\
\text { pertanyaan atau } \\
\text { masukan }\end{array}$ & $\begin{array}{l}\text { Dr Made } \\
\text { Sriasih, }\end{array}$ & $\begin{array}{l}15.00- \\
15.30\end{array}$ \\
\hline 4 & $\begin{array}{l}\text { Tahapan pelaksanaan } \\
\text { pemeriksaan: } \\
\text { a. Registrasi Umum } \\
\text { b. Pemeriksaan } \\
\text { Fisik } \\
\text { c. Masyarakat yang } \\
\text { mendapat } \\
\text { rekomendasi } \\
\text { pemeriksaan } \\
\text { kolesterol dan }\end{array}$ & $\begin{array}{l}\text { Tim } \\
\text { Tim }\end{array}$ & $\begin{array}{l}15.30- \\
\text { Selesai }\end{array}$ \\
\hline
\end{tabular}




\begin{tabular}{|l|l|l|l|}
\hline $\begin{array}{l}\text { glukosa darah } \\
\text { langsung kemeja } \\
\text { Pemeriksaan } \\
\text { konsultasi hasil } \\
\text { pemeriksaan dan } \\
\text { pemberian obat }\end{array}$ & Apt, Nur & Atikah, \\
& M,Sc & \\
\hline
\end{tabular}

Program pengabdian masyakat ini dilaksanakan di lingkungan Bawaq Bageq Utara kelurahan Dasan Agung kecamatan Selaparang kota Mataram pada tanggal 27 Desember 2019 pukul 15.45 Wita

\section{Gambar dan Tabel}

Hasil pemeriksaan kesehatan terhadap 37 warga desa Bawaq Bageq Utara diperoleh hasil sebagai berikut:

Tabel 2. Tabel Hasil Pengukuran Tekanan Darah

\begin{tabular}{|l|l|}
\hline Kategori & Jumlah Warga \\
\hline Normal & 7 \\
\hline Pre Hipertensi & 9 \\
\hline Hipertensi & 21 \\
\hline $\begin{array}{l}\text { Tabel 3. Tabel Hasil pengukuran Kad } \\
\text { Cholesterol }\end{array}$ \\
\begin{tabular}{|l|l|}
\hline Kategori & \multicolumn{2}{|}{ Jumlah warga } \\
\hline Normal <200 & 14 \\
\hline $200-239$ & 7 \\
\hline$>240$ & 16 \\
\hline
\end{tabular}
\end{tabular}

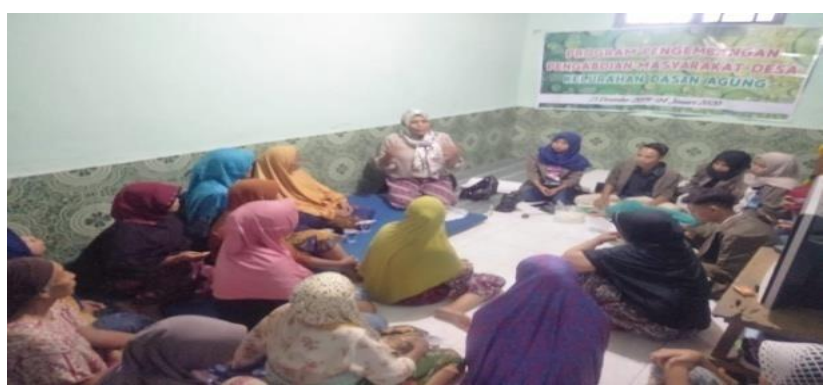

Gambar 1 Penyuluhan tentang DM dan Hiperkolestrol

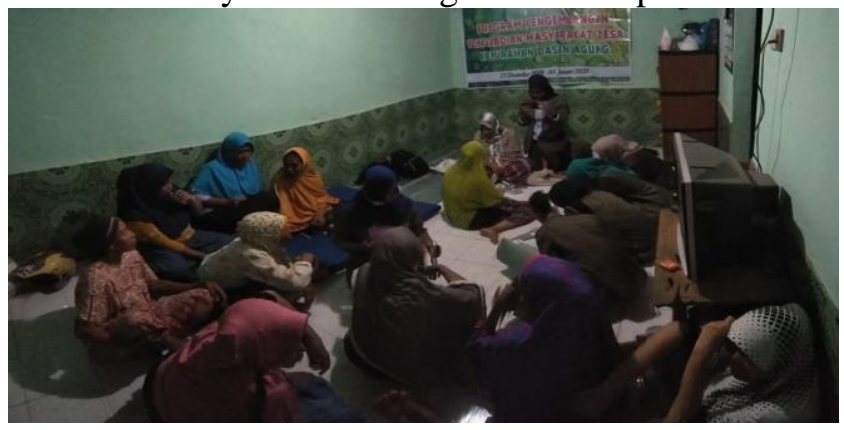

Gambar 2 Pemeriksaan kesehatan

\section{Hasil dan Pembahasan}

Pemeriksaan yang dilakukan terhadap 37 warga Bawaq Bageq Utara yang terdiri dari 6 orang laki - laki dan 31 orang perempuan. Umur warga yang melakukan pemeriksaan kesehatan adalah rata rata diatas 40 tahun hanya 7 (satu) orang yang berusia di bawah 40 tahun.

Selain mendapatkan manfaat dengan mengetahui hasil pegukuran kadar glukosa darah dan kolesterol hasil lain yang diperoleh dari kegiatan pengabdian ini,baik bagi masyarakat maupun bagi pelaksana. Diantaranya dapat dikemukakan sebagai berikut:

1. Masyakat mengetahui kadar dari pemeriksaan yang dilakukan. Sehingga warga yang melakukan pemeriksaan dan yang memiliki kadar gkulosa darah dan atau kolesterol yang berlebih dapat segera melakukan pemeriksaan selanjutnya untuk diagnosis dalam rangkan pencegahan terjadinya komplikasi

2. Masyarakat lebih memahami pentingnya melakukan pemeriksaan sebagai deteksi diri terhadap diabetes mellitur dan hiperkolesterol.

3. Meningkatnya pengetahuan pelaksana kegiatan tentang penyakit DM dan hiperkolestrol

Hasil dari kegiatan pengabdian ini juga dapat diketahui adanya hipertensi dan hiperkolesterol. Manfaatnya sebagai deteksi, diagnosis dan pencegahan komplikasi. Dengan mengetahui lebih dini sehingga dapat dicegah adanya komplikasi akibat hipertensi. Hipertensi yang tidak terkontrol akan memiliki dampak terhadap kesehatan seperti kerjadinya stroke, kerusahan ginjal dan penyakit jantung koroner. Deteksi adanya hipertensi lebih awal sehingga dapat dilakukan monitoring untuk mempertahankan tekanan darah dalam kondisi normal. Pengobatan terhadap hipertensi dapat dilakukan secara farmakologis dan non 
farmakologis. Pengobatan secara farmakologis dilakukan dengan pemberian anti hipertensi. Pengobatan secara non farmakologis dapat dilakukan dengan seperti dengan mempertahankan berat badan ideal atau rutin melakukan aktivitas fisik (Glenys, 2017)

Pada Hiperkolesterol pengobatan dilakukan secara farmakologis dan non farmakologis. Pengobatan non farmakologis dilakukan dengan diet. Kondisi hiperkolesterolemia yang melibatkan obesitas dan pemilihan diet yang tidak tepat diketahui juga dapat menyebabkan kerusakan sel hati (Kaplowitz, 2002)

Penelitian yang dilakukan oleh Rizatriana didapatkan pengetahuan akan penyakit dan diet DM adalah baik. Tetapi ada beberapa penelitian yang menyatakan bahwa kurangnya pengetahuan masyarakat tentang DM menyebabkan masyarakat untuk tidak mematuhi pengobatan, dan pengontrolan gula darah (Agustina Meldy Rika et al., 2017). Pengetahuan tingkat awal yang harus diperkenalkan pada pasien DM adalah perjalanan penyakit DM, pengendalian dan pemantauan DM, penyulit DM, terapi farmakologi dan non farmakologis, interaksi antara asupan makanan dengan aktifitas fisik serta olahraga, cara pemantauan glukosa darah mandiri, mengatasi hipoglikemia, pentingnya olahraga, perawatan kaki dan menggunakan fasiliitas kesehatan yang ada (Soelistijo et al., 2015)

Sebagai langkah awal untuk mengurangi angka DM di Indonesia politeknik "Medica Farma Husada" Mataram memberikan edukasi atau pengetahuan kepada masyarakat tentang DM. Pengetahuan itu akan menjadi langkah awal masarakat untuk melakukan perubahan sikap dan gaya hidup sehingga nantinya akan meningkatkan kualitas hidup masyarakat. Dan masyarakat yang memiliki gula darah yang tinggi nantinya memiliki penegetahuan tentang pola hidup yang sehat.

Menurut (Notoatmodjo, 2010) yang menyatakan bahwa salah satu faktor yang menentukan perilaku kesehatan seseorang adalah tingkat pengetahuan. Menurut
(Soewondo P., 2005) dengan meningkatnya pengetahuan pasien DM dapat melakukan penatalaksanaan penyakitnya sehingga kondisi kesehatan pasien menjadi lebih baik. Dimana monitor glukosa darah merupakan hal utama dalam pengelolaan penyakit DM. Pemantauan kadar glukosa darah merupakan bagian yang tak terpisahkan dari pengelolaan DM, karena dengan pengendalian kadar glukosa darah yang baik dapat menurunkan risiko terjadinya komplikasi kronis diabetes.

\section{Kesimpulan}

bahwa masyarakat hanya melakukan pemeriksaan ketika mereka mengalami keluhan saja dan dengan adanya kegiatan ini membantu masyarakat, tenaga kesehatan untuk mendeteksi penyakit lebih awal, karena masih banyak masyarakat yang belum paham untuk melakukan pemeriksaan kesehataan secara berkala maka kegiatan seperti ini perku dilakukan untuk mengajak masyarakat melakukan pemeriksaan kesehatan.

\section{Ucapan terima kasih}

Penulis dan tim Pengabdian mengucapkan terima kasih kepada Kepala Lingkungan Bawaq bageq bawak lurah Dasan Agung, Mahasiswa Program Pengembangan dan Pengabdian Pada Masyarkat Desa (P3MD), Kader Desa dan Lembaga Penelitian dan Pengabdian Masyarakat (LPPM) Politeknik Medica Farma Husada Mataram dan LPPM Universitas Mataram yang telah memberi dukungan terhadap kegiatan pengabdian masyarakat ini.

\section{Daftar Pustaka}

Agustina Meldy Rika, Noor, D., \& Agianto. (2017). Hubungan Pengetahuan Dan Perilaku Pasien Tentang Penatalaksanaan Diabetes Mellitus Di Banjarbaru Kalimantan Selatan. Nusantara Medical Science Journal, 14-18. 
Depkes, R. I. (2003). Pedoman pengelolaan kegiatan kesehatan di kelompok lanjut usia.

Glenys. (2017). Penatalaksanaan Hipertensi Primer. Majority, 6(1), 25-33.

Kaplowitz, G. J. (2002). An aid to proximal wall reduction for full crowns. Journal of the American Dental Association, 133 , 72. http://dx.doi.org/10.14219/jada.archive. 2002.0024

Notoatmodjo, S. (2010). Metodologi Penelitian Kesehatan. Rineka cipta.

Soelistijo, S., Novida, H., Rudijanto, A., Soewondo, P., Suastika, K., Manaf, A., Sanusi, H., Lindarto, D., Shahab, A., Pramono, B., Langi, Y., Purnamasari, D., \& Soetedjo, N. (2015). Konsesus Pengelolaan Dan Pencegahan Diabetes Melitus Tipe2 Di Indonesia 2015. In Perkeni.

https://www.google.com/url?sa=t\&sour $\mathrm{ce}=$ web\&rct $=\mathrm{j} \&$ url $=\mathrm{https}: / /$ pbperkeni.or .id/wp-content/uploads/2019/01/4.-

Soewondo P. (2005). Pemantauan Pengendalian Diabetes Melitus. Balai Penerbit FK UI, pp. 153-9. .

World Health Organization. (2016). Global Report on Diabetes.

Mahatidanar, Andika.2015. Manfaat Buah apel (Malus domestica) untuk pencegahan stroke pada pasien kolestrol tinggi. J Angromed Unila

World Health Organization. (2016). Global Report on Diabetes. 